\title{
Epidural Ropivacaine Alone or Combined With Fentanyl in Infraumblical Surgeries: A Comparative Study
}

\author{
Authors \\ Rakesh Bahadur Singh ${ }^{1}$, Dheer Singh ${ }^{2}$, Manoj Kumar ${ }^{3}$, Prashant K Mishra ${ }^{4}$ \\ 1,2,3,4 Department of Anaesthesiology, UP RIMS\&R, Saifai, Etawah, UP, India \\ Corresponding Author \\ Dr Manoj Kumar \\ Department of Anaesthesiology, UP RIMS\&R, Saifai, Etawah,UP, India \\ Email: lucknow.manoj@gmail.com
}

\begin{abstract}
Epidural blockade is becoming one of the most useful and versatile procedures in modern anaesthesiology. We compared intensity of sensory \& motor blockade, duration of analgesia and hemodynamic changes in 45 patients belonged to ASA grade-I or II, between 20 and 55 years of age, among Gr-I ( $0.75 \%$ Ropivacaine) and Gr-II (0.75\% Ropivacaine + $50 \mathrm{mcg}$ Fentanyl), requiring central neuraxial blockade for infraumlical surgeries. We concluded that the fentanyl when added as an adjuvant to epidural ropivacaine, significantly prolongs the analgesic duration without causing significant haemodynamic and respiratory changes. And with this combination there is no significant change in the level of sensory and motor blockade.
\end{abstract}

Key words- ropivacaine, fentanyl, epidural

\section{INTRODUCTION}

Epidural blockade is becoming one of the most useful and versatile procedures in modern anaesthesiology. It is unique in that it can be placed at virtually any level of the vertebrae, allowing more flexibility in its application to clinical practice. It's versatility, giving the clinician the opportunity to provide anaesthesia and analgesia, used to supplement general anaesthesia, decreasing the need for deep levels of general anaesthesia and therefore providing a more haemodynamically stable operative course. In such patients it can provide a relief from pain for a longer duration and the facility of further top-ups and continuous infusion of the analgesic drugs through epidural catheter thus provides an uneventful and smooth recovery. In recent years, ropivacaine has increasingly replaced bupivacaine for the adequate post-op pain relief in patients undergoing lower abdominal surgeries, because of its similar analgesic properties, lesser motor blockade and decreased propensity of cardiotoxicity ${ }^{1}$.

Opioids, given by epidural route to relieve post-op pain, may provide adequate analgesia when given in low doses, but can also cause mental confusion, somnolence, nausea and vomiting, itching and respiratory depression when given in high doses ${ }^{2}$. 
Local anaesthetic and opioid combination was shown to be more effective in epidural analgesia for post-op pain as their effects started rapidly and lasted longer when compared with local anaesthetics given alone ${ }^{3}$.

The main site of action of fentanyl is the substantia gelatinosa in the dorsal horn of spinal cord, where it blocks the neural fibres carrying pain impulses both at pre-synaptic and post synaptic levels ${ }^{4}$. As fentanyl has no effect on sympathetic and motor neurons, it has advantages over local anaesthetics. Addition of opioid to local anaesthetics gives the opportunity to use more diluted local anaesthetic solutions for better analgesia, and reduces systemic toxicity risk and motor block incidence of local anaesthetics ${ }^{5}$.

Keeping all these pharmacological interactions in consideration, we planned a prospective, randomized, double-blind, clinically controlled trial in our institute.

\section{REVIEW OF LITERATURE}

In recent years, ropivacaine has been increasingly replacing bupivacaine for the epidural anesthesia and analgesia because of its similar analgesic properties. $^{6,7}$ lesser motor blockade ${ }^{6,7}$ and decreased propensity of cardiotoxicity ${ }^{8,9}$. Ropivacaine is a long-acting amide local anaesthetic agent with high Pka, low lipid solubility and structurally related to Bupivacaine. It is first pure $S(-)$ enantiomer, unlike Bupivacaine which is a racemate.

The greater safety of ropivacaine than bupivacaine may be related both, to the reduced toxicity of the single (S)-isomer and to the difference between the propyl- and butyl-Npiperidine substituent. The very slow reversal of $\mathrm{Na}+$ channel blockade after a cardiac action potential, which is a hallmark of bupivacaine, is considerably faster with ropivacaine. In addition to these electrical differences, the negative inotropic potency of ropivacaine on isolated cardiac tissue appears to be considerably less than that of bupivacaine ${ }^{10,11}$.
Fentanyl is a potent synthetic narcotic analgesic with a rapid onset and short duration of action. The main site of action of fentanyl is the substantia gelatinosa in the dorsal horn of spinal cord, where it blocks the neural fibres carrying pain impulses both at pre-synaptic and post synaptic levels ${ }^{12}$. Analgesic effects of epidural opioids are influenced by a number of pharmacokinetic factors including, the mode of drug delivery, with infusions resulting in lower dose requirements ${ }^{\mathbf{1 3}}$ the high lipophilicity of fentanyl, its rapid penetration across the dura, ${ }^{14}$ its nonspecific binding in the spinal cord, its possible uptake by dural fat tissues, and its systemic absorption make its pharmacokinetics very complex when administered epidurally ${ }^{\circ}$ Fentanyl (lipophilic opioid) is often preferred to morphine (hydrophilic opioid) because of its more limited rostral spread within the intrathecal space ${ }^{15}$.

Scott DA et al (1999) conducted a randomized, double-blinded study to compare the analgesic effectiveness and side effects of epidural infusions with ropivacaine $2 \mathrm{mg} / \mathrm{mL}$ alone and in combination with fentanyl $1 \mathrm{microg} / \mathrm{mL}$, $2 \mathrm{microg} / \mathrm{mL}$ and $4 \mathrm{microg} / \mathrm{mL}$. They conclude that, after major abdominal surgery, an epidural infusion of ropivacaine $2 \mathrm{mg} / \mathrm{mL}$ with fentanyl $4 \mathrm{micro} / \mathrm{mL}$ provided significantly more effective pain relief over a 3-day period than ropivacaine alone or ropivacaine with lower concentrations of fentanyl ${ }^{16}$.

David C. Campbell et al (1999) conducted a prospective, randomized, double-blinded study designed to compare the efficacy of $20 \mathrm{~mL}$ of either $0.08 \%$ bupivacaine plus $2 \mu \mathrm{g} / \mathrm{mL}$ fentanyl or $0.08 \%$ ropivacaine plus $2 \mu \mathrm{g} / \mathrm{mL}$ fentanyl to initiate ambulatory labour epidural analgesia. The results of their study indicate that dilute ropivacaine combined with fentanyl effectively initiates epidural analgesia while concurrently preserving maternal ability to void and ambulate ${ }^{17}$.

Amanda J. Pinder et al (2000) Meister et al. compared epidural analgesia with $0.125 \%$ 
ropivacaine/fentanyl

versus

$0.125 \%$

bupivacaine/fentanyl during obstetric labor. The authors state that ropivacaine cannot be less potent than bupivacaine as less supplemental analgesia was needed in the ropivacaine group ${ }^{18}$.

D J Buggy et al (2000) compared patientcontrolled epidural analgesia (PCEA) with ropivacaine alone or combined with fentanyl. They found that the incidence of motor weakness (Bromage grade 1 or higher) was $48 \%(11 / 23)$ at 8 $\mathrm{h}$ in group $\mathrm{R}$ compared with $13 \%$ (3/24) in group RF $(P=0.025)$..So they concluded that, the caution should be exercised using ropivacaine PCEA after spinal bupivacaine for Caesarean section, because its reputed motor-sparing property may be unreliable ${ }^{19}$.

Lee Wk et al (2003) studied 210 patients undergoing lower abdominal or lower extremity surgery received epidural analgesia infusions at $7 \mathrm{~mL} /$ hour, 105 with $0.1 \%$ ropivacaine and 105 with $0.1 \%$ ropivacaine plus $1 \mathrm{microg} / \mathrm{mL}$ fentanyl. They found that pain relief scores was significantly better in the ropivacaine/ fentanyl group after the first hour and this difference lasted for the remaining time ${ }^{20}$.

Atienzar MC et al (2004) concluded by their study that an epidural infusion of $0.1 \%$ ropivacaine with fentanyl 2 microg $\mathrm{mL}(-1)$ at 10 $\mathrm{mL} h(-1)$ provided adequate analgesia in the first stage of labour. The level of analgesia was similar to that obtained using $0.2 \%$ ropivacaine with fentanyl 2 microg $\mathrm{mL}(-1)$ and with no differences with regard to motor or sensory block ${ }^{21}$.

Shirasaka $\mathbf{T}$ et al (2005) conducted a study to investigate which dose of fentanyl in ropivacaine for epidural anaesthesia will provide effective analgesia with minimal side effects after caesarean section (CS). They concluded that continuous epidural administration of fentanyl 21 microg $\mathrm{x}$ $\mathrm{hr}(-1)$ with ropivacaine provides the optimum balance between pain relief and side effects compared with fentanyl 11 microg $\mathrm{x}$ hr(-1) with ropivacaine after $\mathrm{CS}^{22}$.

Kanai A et al (2007) concluded by their study that continuous epidural infusion of ropivacaine may induce a slower regression of sensory blockade compared with bupivacaine and lidocaine. The addition of fentanyl to ropivacaine can enhance this prolonged analgesic effect with little effect on motor blockade ${ }^{23}$.

Mikhail Y Kirov et al (2011) conducted a study to assess the efficacy of thoracic epidural anaesthesia (EA) followed by postoperative epidural infusion (EI) and patient-controlled epidural analgesia (PCEA) with ropivacaine/fentanyl in off-pump coronary artery bypass grafting (OPCAB). They concluded that in OPCAB, EA with ropivacaine/fentanyl decreases arterial pressure transiently, optimizes myocardial performance and influences the perioperative fluid and vasoactive therapy. Postoperative EI combined with PCEA improves lung function and reduces time to extubation ${ }^{24}$.

\section{MATERIAL AND METHODS}

present study on "Epidural Ropivacaine alone or combined with Fentanyl in infraumblical surgeries- A comparative study" was conducted in Department of Anaesthesiology, Rural Institute of Medical Science and Research, Saifai, Etawah, U.P., India after approval by the ethical committee of the institution, a written consent was taken from the patients after explaining to them in detail about the implications of the anaesthetic and the surgical procedure.

Our study had 45 patients, all patients belonged to ASA grade-I or II, between 20 and 55 years of age requiring neuraxial blockade for lower abdominal surgeries. Patients having morbid obesity, pregnancy, psychiatric disease, history of drug abuse, expected duration of surgery $>2.5$ hours and any contraindication to regional anaesthesia were excluded from the study. Routine investigations were done preoperatively in all the patients.

All the patients were randomly allocated into two groups.

Group-I : Epidural ropivacaine $0.75 \%(14.5 \mathrm{ml})$ $+1.5 \mathrm{ml}$ Distilled water. 
Group-II : Epidural ropivacaine $0.75 \%$ (14.5ml) + Fentanyl $50 \mu \mathrm{gm}(1 \mathrm{ml})+0.5 \mathrm{ml}$ distilled water

All the patients premedicated a night before and on the morning of the surgery with tablet ranitidine $150 \mathrm{mg}$ and tablet alprazolam $0.25 \mathrm{mg}$. The patients were explained about the sequence of anaesthetic procedure and a good IV access was secured. All the patients were preloaded with 500 $\mathrm{ml}$ of $6 \%$ hydroxyl ethyl starch before administration of block and all monitoring devices were attached. The anaesthesia technician was given a written set of guidelines about preparation and blinding of drugs.

Patients were administered epidural block in sitting position/ left lateral position using standard epidural techniques followed by test dose injecting $3 \mathrm{ml}$ of $2 \%$ lignocaine $\mathrm{HCl}$ solution containing adrenaline 1:200,000. After 4-6 minutes of test dose, patients in group-I received $14.5 \mathrm{ml}$ of $0.75 \%$ ropivacaine only while Group-II patients were administered $14.5 \mathrm{ml}$ solution of $0.75 \%$ ropivacaine and $50 \mu \mathrm{gm}$ of fentanyl.

The highest sensory level reached was noted after 20 minutes of administration of the block, it was done by using $25 \mathrm{G}$ hypodermic insulin needle. Similarly regression of sensory level block at the end of procedure was done. Time taken by highest level of block to recede to $T_{10}$ level was recorded in both groups. It was done at time interval of 10 minutes. Surgical procedures were initiated only after the establishment of adequate surgical anaesthetic effect with minimum level up to T6-7 dermatome. Motor block onset and recovery was assessed by Bromage scale at 5, 10, 15, 20, 25, 30, 60, 90 and 120 minute intervals after the epidural administration of the drugs.

Hemodynamic parameters were monitored every 5 minutes until 30 minutes and at 10-minute intervals up to 60 minutes and then at 15-minute intervals for the next hour and finally at 30 minutes in the third hour.

Intravenous fluids were given as per the body weight and operative loss requirement, with no patient requiring blood transfusion. The patients were given supplementary $\mathrm{O}_{2}$ with the help of venturi mask. During the surgical procedure, any adverse event like anxiety, nausea, vomiting, pruritis, shivering, bradycardia, or hypotension was recorded and treated. Hypotension (defined as systolic arterial pressure falling more than $20 \%$ $\mathrm{mm} \mathrm{Hg}$ ) was treated with inj. mephenteramine 3-6 $\mathrm{mg}$ in bolus doses and $\mathrm{HR}<55$ beats/min was treated with $0.3 \mathrm{mg}$ of inj. atropine.

All the patients were kept for 8 hours in recovery room. Apart from vital parameters and any adverse event, all the patients were monitored for degree and duration of pain relief by pain scoring system. Assessment of analgesia was done by analgesia score $(0=$ No pain at rest or with movement, 1 =No pain at rest but pain during voluntary body movement, 2 = Pain at rest but tolerable, 3 = intolerable pain). Patients in both the groups were repeatedly assessed every 10 minutes for pain and rescue analgesic was given when they complained intolerable pain (score-3).

Comparability of the groups was analyzed by Student's two tailed " $t$ " test and chi square test. Student ' $t$ ' test was applied to analyze the parametric data (hemodynamic parameters and block characteristics). For all statistical analysis, the value of $\mathrm{P}<0.05$ was considered as significant and $\mathrm{p}<.001$ was considered most highly significant.

\section{RESULTS}

Highest level of sensory block was found to be T6 in $4(26.6 \%)$ patients of Group-I and 7(46.6\%) patients of group-II. (Table-3)

Mean time for regression of sensory blockade to T10 was significantly longer (Table-4) in group-II $(272.5 \pm 23.51$ minutes $)$ as compared to group I (246 \pm 33.92 minutes).

Highest level of motor blockade was found to be Bromage score-3 in 1(6.66\%) patients of Group-I, and $2(13.33 \%)$ patients of group-II. (Table-5)

The duration of motor blockade was significantly $(\mathrm{p}<0.001)$ higher in (Table-6) patients of Group-II $(196 \pm 17.89$ minutes) as compared to Group-I (169 \pm 19.74 minutes). 


\section{JMSCR Vol.||03||Issue||08||Page 7271-7279||August}

The addition fentanyl (Group-II) produces longer duration (317 \pm 32.80 minutes) of analgesia (Table7) as compared to Group-I (214 \pm 28.42 minutes). Haemodynamically the patients in both the groups behaved similarly. (Table-8)
The patients, in whom epidural fentanyl was used, had slightly higher incidence of nausea, vomiting, dry mouth and pruritis. (Table-9)

Table -1 Distribution of patients according to their demographic data

\begin{tabular}{|l|c|c|}
\hline & $\begin{array}{c}\text { Group -I } \\
\text { (Mean } \pm \text { S.D.) }\end{array}$ & $\begin{array}{c}\text { Group -II } \\
\text { (Mean } \pm \text { S.D.) }\end{array}$ \\
\hline Age(years) & $40.86 \pm 12.03$ & $38.66 \pm 13.27$ \\
\hline Height(cm) & $160.44 \pm 5.562$ & $159.36 \pm 9.405$ \\
\hline Weight(kg) & $52.35 \pm 5.951$ & $55.06 \pm 8.412$ \\
\hline Sex (M:F) & $8: 7$ & $12: 3$ \\
\hline
\end{tabular}

Table-2 Comparison of duration of surgeries in both the groups

\begin{tabular}{|l|c|c|c|c|c|}
\hline Groups & $\begin{array}{c}\text { Total number } \\
\text { of patients }\end{array}$ & Mean duration & S.D. & 't' value & $\begin{array}{c}\text { 'p' } \\
\text { value }\end{array}$ \\
\hline Group-I & 15 & 80.57 & 22.45 & & \\
\hline Group-II & 15 & 82.77 & 19.93 & 0.284 & 0.778 \\
\hline
\end{tabular}

Table -3 Comparison of upper level of sensory block after 20 minutes

\begin{tabular}{|l|c|c|c|c|}
\hline \multirow{2}{*}{ Block height } & \multicolumn{2}{|c|}{ Group I } & \multicolumn{2}{c|}{ Group II } \\
\cline { 2 - 5 } & No. & $\%$ & No. & $\%$ \\
\hline T6 & 4 & 26.66 & 7 & 46.66 \\
\hline T8 & 10 & 66.66 & 8 & 53.33 \\
\hline T10 & 1 & 6.66 & - & - \\
\hline Total & 15 & 100 & 15 & 100 \\
\hline
\end{tabular}

Table -4 Time to regress to T10 level in both groups

\begin{tabular}{|l|c|c|c|}
\hline & Mean \pm S.D. & ' t' value & 'p' value \\
\hline Group I & $246 \pm 33.92$ & 2.40 & $<0.05$ \\
\cline { 1 - 2 } Group II & $272.5 \pm 23.51$ & & \\
\hline
\end{tabular}

Table -5 Comparison of Motor block (Bromage score) after 30 minutes in both groups

\begin{tabular}{|l|c|c|c|c|}
\hline \multirow{2}{*}{ Bromage score } & \multicolumn{2}{|c|}{ Group I } & \multicolumn{2}{c|}{ Group II } \\
\cline { 2 - 5 } & No. & $\%$ & No. & $\%$ \\
\hline 1 & 0 & 0 & 0 & 86.66 \\
\hline 2 & 14 & 93.33 & 13 & 13.33 \\
\hline 3 & 1 & 6.66 & 2 & 0 \\
\hline 4 & 0 & 0 & 0 & 100 \\
\hline Total & 15 & 100 & 15 & \\
\hline
\end{tabular}

Table-6 Comparison of time for Motor block Recovery ( Bromage score 1)

\begin{tabular}{|l|c|c|c|}
\hline & Mean \pm S.D. & ' $\mathbf{t}$ ' value & ' $\mathbf{p}$ ' value \\
\hline Group I & $169 \pm 19.74$ & 3.79 & $<0.001$ \\
\cline { 1 - 2 } Group II & $196 \pm 17.89$ & & \\
\hline
\end{tabular}


Table -7 Comparison of rescue analgesia time (in minutes) in different groups

\begin{tabular}{|l|c|c|c|}
\hline & Mean \pm S.D. & ' t' value & 'p' value \\
\hline Group I & $214 \pm 28.42$ & 9.192 & $<0.001$ \\
\cline { 1 - 2 } Group II & $317 \pm 32.80$ & & \\
\hline
\end{tabular}

Table-8 Comparison of hemodynamic parameters in both groups at different time interval

\begin{tabular}{|c|c|c|c|c|c|c|c|c|c|c|c|c|}
\hline \multirow{3}{*}{$\begin{array}{l}\text { Time } \\
\text { intervals }\end{array}$} & \multicolumn{6}{|c|}{ Pulse rate } & \multicolumn{6}{|c|}{ Mean arterial blood pressure } \\
\hline & \multicolumn{3}{|c|}{ Group I } & \multicolumn{3}{|c|}{ Group II } & \multicolumn{3}{|c|}{ Group I } & \multicolumn{3}{|c|}{ Group II } \\
\hline & $\begin{array}{l}\text { Mean } \\
\pm \text { SD }\end{array}$ & $\begin{array}{l}\text { 't' } \\
\text { value }\end{array}$ & $\begin{array}{l}\text { 'p' } \\
\text { value }\end{array}$ & $\begin{array}{l}\text { Mean } \\
\pm \text { SD }\end{array}$ & $\begin{array}{l}\text { 't' } \\
\text { value }\end{array}$ & $\begin{array}{l}\text { 'p' } \\
\text { value }\end{array}$ & $\begin{array}{l}\text { Mean } \\
\pm \text { SD }\end{array}$ & $\begin{array}{l}\text { 't' } \\
\text { value }\end{array}$ & $\begin{array}{l}\text { 'p' } \\
\text { value }\end{array}$ & $\begin{array}{l}\text { Mean } \\
\pm \text { SD }\end{array}$ & $\begin{array}{l}\text { 't' } \\
\text { value }\end{array}$ & $\begin{array}{l}\text { 'p' } \\
\text { value }\end{array}$ \\
\hline 15 minutes & $\begin{array}{l}87.06 \\
+5.94\end{array}$ & 2.276 & .03 & $\begin{array}{l}83.33 \\
\pm 8.56\end{array}$ & 0.953 & .348 & $\begin{array}{l}87.40 \\
+5.53\end{array}$ & 4.373 & $\begin{array}{l}.0002 \\
*\end{array}$ & $\begin{array}{l}85.8 \\
+5.65\end{array}$ & 4.093 & $\begin{array}{l}.0003 \\
*\end{array}$ \\
\hline 30 minutes & $\begin{array}{l}83 \\
\pm 6.31\end{array}$ & 0.902 & $\begin{array}{l}.374 \\
!\end{array}$ & $\begin{array}{l}79.13 \\
\pm 8.50\end{array}$ & 0.201 & $\begin{array}{l}.844 \\
!\end{array}$ & $\begin{array}{l}87.60 \\
\pm 4.71\end{array}$ & 4.478 & $\begin{array}{l}.0001 \\
*\end{array}$ & $\begin{array}{l}86.13 \\
\pm 7.64\end{array}$ & 3.684 & $\begin{array}{l}.001 \\
*\end{array}$ \\
\hline 60 minutes & $\begin{array}{l}80.86 \\
\pm 9.37\end{array}$ & 0.170 & $\begin{array}{l}.866 \\
!\end{array}$ & $\begin{array}{l}76.53 \\
\pm 9.63\end{array}$ & 0.873 & $\begin{array}{l}.390 \\
!\end{array}$ & $\begin{array}{l}87.86 \\
\pm 6.6\end{array}$ & 3.966 & $\begin{array}{l}.0005 \\
*\end{array}$ & $\begin{array}{l}87.93 \\
\pm 5.68\end{array}$ & 3.422 & $\begin{array}{l}.0019 \\
*\end{array}$ \\
\hline $\begin{array}{l}120 \\
\text { minutes }\end{array}$ & $\begin{array}{l}78 \\
\pm 9.04\end{array}$ & 0.652 & $\begin{array}{l}.519 \\
!\end{array}$ & $\begin{array}{l}73.8 \\
\pm 10.02\end{array}$ & 1.561 & $\begin{array}{l}.129 \\
!\end{array}$ & $\begin{array}{l}85.00 \\
\pm 5.52\end{array}$ & 5.276 & $\begin{array}{l}0.000 \\
*\end{array}$ & $\begin{array}{l}86.26 \\
\pm 6.00\end{array}$ & 3.897 & $\begin{array}{l}.0006 \\
*\end{array}$ \\
\hline
\end{tabular}

!- insignificant, *- significant

Table-9 Comparison of side effects in both the groups

\begin{tabular}{|l|c|c|}
\hline Side effect & Group I & Group II \\
\hline Immediate & 02 & 03 \\
Nausea/vomiting & 07 & 08 \\
Hypotension & 00 & 00 \\
Bradycardia & 01 & 04 \\
Dry mouth & 05 & 04 \\
Shivering & 00 & 02 \\
Pruritis & 01 & 02 \\
Urinary Retention & & \\
\hline Delayed & 00 & 00 \\
Infection & 01 & 00 \\
Post-dural Puncture headache & 00 & 00 \\
Acute neurological Sequele & & \\
\hline
\end{tabular}

\section{DISCUSSION}

Katz JA et al (1990) studied 15 patients of ASA I or II for elective lower-extremity orthopedic procedures using a nonrandomized open-label design. Three groups of five patients each received either $0.5 \%, 0.75 \%$, or $1.0 \%$ ropivacaine. Upper and lower levels of analgesia to pinprick were determined at frequent intervals until normal sensation had completely returned. They found that median maximum thoracic levels of analgesia achieved were 8,6 , and 5 for the $0.5 \%, 0.75 \%$, and $1.0 \%$ groups, respectively, and occurred at 29 +/- 11, 37 +/- 21, and $30+/-9$ min. Respective times to two-segment regression were $2.8+/-1.0$,
$3.0+/-0.5$, and $2.9+/-0.6$ hours. Total durations of sensory blockade were $5.4+/-0.7,6.5+/-0.4$, and $6.8+/-0.8$ hours, respectively ${ }^{25}$.

In our study, In 20 out of 45 patients, T6 sensory blockade was achieved at 20 minutes, while 24 out of 45 patients achieved T8 sensory level. Time to regress to T10 level in all the three groups were $246 \pm 33.92,272 \pm 23.51,354 \pm 55$ in group-I,II,III respectively. Thus our results were comparable with the above study.

Kanai A et al (2007) studies 80 patients, scheduled for orthopaedic procedures of the lower extremity under lumbar epidural anaesthesia. Following the operation, continuous infusion of a 
randomized solution $(0.2 \%$ ropivacaine, $0.125 \%$ bupivacaine, $0.5 \%$ lidocaine, or $0.2 \%$ ropivacaine with $2.5 \mathrm{microg} / \mathrm{mL}$ fentanyl) was commenced at a rate of $6 \mathrm{~mL} / \mathrm{h}$. The regression of sensory and motor blockade were compared among the groups. They found that the regression of sensory blockade was significantly prolonged in patients treated with ropivacaine. The addition of fentanyl to ropivacaine augmented this prolonged analgesic effect. So they concluded that epidural infusion of ropivacaine with fentanyl provides effective pain relief, possibly because of the maintenance of sensory blockade by ropivacaine and enhancement of this sensory blockade by fentanyl ${ }^{23}$.

In our study prolongation of mean time for regression of sensory blockade to T10 was significant $(\mathrm{p}<0.05)$ between group-I \& group-II and highly significant $(\mathrm{p}<0.001)$ between groups II \& III and I \& III, which is comparable to above study.

Meister G $\mathbf{C}$ et al (2000) concluded that, the epidural ropivacaine $0.125 \%$ with fentanyl $2 \mu \mathrm{g} / \mathrm{mL}$ produces similar labour analgesia with significantly less motor block than an equivalent concentration of bupivacaine/Fentanyl ${ }^{26}$. After statistical evaluation we found that difference in mean values between groups-I \& II and in groupsI \& III were most highly significant $(\mathrm{p}<0.001)$ while it was significant between Groups-II \& II (p $<0.01$ ).

Shirasaka $\mathbf{T}$ et al (2005) conducted a study to investigate which dose of fentanyl in ropivacaine for epidural anaesthesia will provide effective analgesia with minimal side effects after caesarean section (CS). 58 patients scheduled for CS were randomly allocated into two groups according to fentanyl dose in epidural analgesia: group F1 (11 microg x hr(-1); $\mathrm{n}=30$ ) or group F2 (21 microg x $\mathrm{hr}(-1) ; \mathrm{n}=28)$. Ropivacaine $0.2 \% 100 \mathrm{ml}$ with fentanyl 400 or 800 microg was administered into the epidural space in the groups F1 and F2, respectively. They found that pain scores with cough or movement were significantly lower in the group F2 than the group F1 at twelve and twenty-four hours after CS and Bromage score at twelve hours was lower in the group F2 than the group $\mathrm{F} 1^{22}$.

In the present study, we found that, the duration of motor blockade was significantly $(\mathrm{p}<0.001)$ higher in group-II \& III patients as compared to group-I. This is comparable to above study.

\section{CONCLUSION}

So this study re-established the fact, that the fentanyl when added as an adjuvant to epidural ropivacaine, significantly prolongs the analgesic duration without causing significant haemodynamic and respiratory changes. And with this combination there is no significant change in the level of sensory and motor blockade.

\section{REFERENCES}

1. Katz JA, Bridenbaugh PO, Knarr DC, Helton SH, Denson DD. Pharmacodynamics and pharmacokinetics of epidural ropivacaine in humans. Anesth Analg 1990;70:16-21.

2. Rockemann MG, Seeling W, Brinkmann A, Goertz AW, Hauber N, Junge J, et al. Analgesic and hemodynamic effects of epidural clonidine, clonidine/morphine and morphine after pancreatic surgery: A double-blind study. Anesth Analg 1995;80:869-74.

3. Ozalp G, Guner F, Kuru N, Kadiogullari N. Postoperative patient-controlled epidural analgesia with opioid bupivacaine mixtures. Can J Anaesth 1998;45:938-42.

4. Cousins MJ, Mather LE. Intrathecal and epidural administration of opioids. Anesthesiology 1984;61:276-310.

5. Turner G, Scott DA. A comparison of epidural ropivacaine infusion alone and with three different concentration of fentanyl for 72 hours of postoperative analgesia following major abdominal surgery. Reg Anesth 1998;23:A39.

6. Mc Clure JH. Ropivacaine. Br J Anaesth 1996;76:300-7. 
7. Markham A, Faulds D. Ropivacaine: A review of its pharmacology and therapeutic use in regional anaesthesia. Drugs 1996;52:429- 49.

8. Katz JA, Bridenbaugh PO, Knarr DC, Helton SH, Denson DD. Pharmacodynamics and pharmacokinetics of epidural ropivacaine in humans. Anesth Analg 1990;70:16-21.

9. Reiz S, Häggmark S, Johansson G, Nath S. Cardiotoxicity of ropivacaine: A new amide local anaesthetic agent. Acta Anaesthesiol Scand 1989;33:93-8.

10. Pitkanen M, Feldman HS, Arthur GR, Covino BG: Chronotropic and inotropic effects of ropivacaine, bupivacaine, and lidocaine in the spontaneously beating and electrically paced isolated, perfused rabbit heart. Reg Anesth 1992; 17:183-192.

11. Moller R, Covino BG: Cardiac electrophysiologic properties of bupivacaine and lidocaine compared with those of ropivacaine, a new amide local anesthetic. Anesthesiology 1990; 72:322-329.

12. Cousins MJ, Mather LE. Intrathecal and epidural administration of opioids. Anesthesiology 1984;61:276-310.

13. El-Baz NMI, Faber LP, Jensik RJ. Continuous epidural infusion of morphine for treatment of pain after thoracic surgery: a new technique. Anesth Analg 1984;63: 757-64

14. Gourlay GK, Murphy TM, Plummer $\mathrm{JL}$, et al. l'bannacokinetics of fentanyl in lumbar and cervical CSF following lumbar epidural and intravenous administration. Pain 1989;38:253-9.

15. Gourlay GK, Cherry DA, Cousins MJ. Cephalad migration of morphine in CSF following lumbar epidural administration in patients with cancer pain. Pain 1985;23:317-26.

16. Scott DA, Blake D, Buckland M, et al. A comparison of epidural ropivacaine infusion alone and in combination with 1 ,
2, and $4 \mathrm{microg} / \mathrm{mL}$ fentanyl for seventytwo hours of postoperative analgesia after major abdominal surgery Anesth Analg. 1999 Apr;88(4):857-64.

17. David C. Campbell, MD et al. Ambulatory Labor Epidural Analgesia: Bupivacaine Versus Ropivacaine. Anesthesia \& Analgesia. June 2000 vol. 90 no. 6 1384-138.

18. Amanda J. Pinder. Ropivacaine and Bupivacaine with Fentanyl for Labor Epidural Anesthesia. Anesth Analg: October 2000;91:5:1310-1311.

19. Buggy DJ, Hall NA, Shah J, Brown J, Williams J. Motor block during patientcontrolled epidural analgesia with ropivacaine or ropivacaine/fentanyl after intrathecal bupivacaine for caesarean section. Br J Anaesth. 2000 Sep;85(3):468-70.

20. Lee WK, Yu KL,et al. Ropivacane $0.1 \%$ with or without fentanyl for epidural postoperative analgesia: a randomized, double-blind comparison. Kaohsiung J Med Sci. 2003 Sep;19(9):458-63.

21. Atienzar MC, Palanca JM, Borras R, Esteve I, Fernandez M, Miranda A. Ropivacaine $0.1 \%$ with fentanyl 2 microg $\mathrm{mL}(-1)$ by epidural infusion for labour analgesia. Eur J Anaesthesiol 2004;21: 770-5.

22. Shirasaka T, Yonaha T, Ookubo S, Nishimura E, Kashiwada M, Takasaki M. Optimal dose of fentanyl for postoperative epidural analgesia after cesarean section. Masui. 2005 Sep;54(9):1008-13.

23. Kanai A, Osawa S,et al. Regression of sensory and motor blockade, and analgesia during continuous epidural infusion of ropivacaine and fentanyl in comparison with other local anesthetics. Pain Med. 2007 Oct-Nov;8(7):546-53.

24. Mikhail Y Kirov, Alexey V Eremeev, et al. Epidural anesthesia and postoperative analgesia with ropivacaine and fentanyl in off-pump coronary artery bypass grafting: a randomized, controlled study. BMC 
Anesthesiology 2011, 11:17

doi:10.1186/1471-2253-11-1.

25. Katz JA, Bridenbaugh PO, Knarr DC, Helton SH, Denson DD. Pharmacodynamics and pharmacokinetics of epidural ropivacaine in humans. Anesth Analg 1990;70:16-21.

26. Meister GC, D’Angelo R, Owen M, et al. A comparison of epidural analgesia with $0.125 \%$ ropivacaine with fentanyl versus $0.125 \%$ bupivacaine with fentanyl during labor. Anesth Analg 2000; 90: 632-7. 